Supporting Information

\title{
Effect of 1-Substitution on
}

\section{Tetrahydroisoquinolines as Selective Antagonists for the Orexin-1 Receptor}

David A. Perrey, ${ }^{\dagger}$ Nadezhda A. German, ${ }^{\dagger}$ Ann M. Decker, ${ }^{\dagger}$ David Thorn, ${ }^{\dagger}$ Jun-Xu Li,${ }^{+\dagger}$ Brian P. Gilmour,,$^{\dagger}$ Brian F. Thomas, ${ }^{\dagger}$ Danni L. Harris, ${ }^{\dagger}$ Scott P. Runyon, ${ }^{\dagger}$ and Yanan Zhang, ${ }^{\dagger, *}$

${ }^{\dagger}$ Research Triangle Institute, Research Triangle Park, North Carolina 27709

${ }^{\ddagger}$ Department of Pharmacology and Toxicology, University at Buffalo, the State University of New York, Buffalo, New York 14214, United States

\section{Table of Contents}

1. HPLC purity and retention times

S2 
Table S1. HPLC Purity and retention times of final compounds

\begin{tabular}{|c|c|c|}
\hline Number & Ret time (min) & Purity (\% area) \\
\hline 12 & 14.72 & 100 \\
\hline 13 & 18.75 & 100 \\
\hline 14 & 20.88 & 100 \\
\hline 15 & 13.77 & 100 \\
\hline 16 & 18.44 & 95.7 \\
\hline 17 & 16.35 & 100 \\
\hline 18 & 18.87 & 100 \\
\hline 19 & 20.33 & 100 \\
\hline 20 & 19.23 & 100 \\
\hline 21 & 13.59 & 100 \\
\hline 22 & 13.24 & 100 \\
\hline 23 & 18.61 & 100 \\
\hline 26 & 12.51 & 97.6 \\
\hline 28 & 16.52 & 98.1 \\
\hline 29 & 15.83 & 96.3 \\
\hline 30 & 18.35 & 97.1 \\
\hline 31 & 13.83 & 95.2 \\
\hline 32 & 17.85 & 97.4 \\
\hline 33 & 17.13 & 100 \\
\hline 34 & 15.03 & 100 \\
\hline 35 & 16.84 & 95.2 \\
\hline 36 & 16.07 & 100 \\
\hline 37 & 16.28 & 95.8 \\
\hline
\end{tabular}




\begin{tabular}{|c|c|c|}
\hline 38 & 15.81 & 100 \\
\hline 41 & 18.25 & 96.0 \\
\hline 42 & 16.41 & 98.4 \\
\hline 43 & 12.04 & 95.6 \\
\hline 44 & 12.51 & 100 \\
\hline 45 & 18.71 & 97.3 \\
\hline 46 & 15.43 & 96.5 \\
\hline 47 & 12.04 & 100 \\
\hline 48 & 12.33 & 98.0 \\
\hline 49 & 14.04 & 97.1 \\
\hline 50 & 18.83 & 100 \\
\hline 51 & 19.04 & 97.7 \\
\hline 52 & 15.92 & 95.4 \\
\hline 53 & 18.15 & 96.3 \\
\hline 54 & 23.96 & 97.8 \\
\hline 55 & 15.31 & 100 \\
\hline 56 & 17.81 & 97.3 \\
\hline 59 & 15.60 & 100 \\
\hline 60 & 21.19 & 98.1 \\
\hline 61 & 15.83 & 100 \\
\hline 62 & 13.65 & 100 \\
\hline 63 & 18.35 & 100 \\
\hline 64 & 16.68 & 100 \\
\hline 65 & 16.41 & 100 \\
\hline 66 & 19.65 & 100 \\
\hline 67 & 18.45 & 100 \\
\hline
\end{tabular}




\begin{tabular}{c|c|c}
\hline $\mathbf{6 8}$ & 19.44 & 97.6 \\
\hline $\mathbf{6 9}$ & 27.21 & 99.4 \\
\hline $\mathbf{7 3}$ & 19.33 & 97.1 \\
\hline
\end{tabular}

